\title{
Genome-wide identification of CAMTA gene family members in Medicago truncatula and their expression during root nodule symbiosis and hormone treatments
}

\author{
Yanjun Yang, Tao Sun, Luqin Xu, Erxu Pi, Sheng Wang, Huizhong Wang and \\ Chenjia Shen *
}

College of Life and Environmental Sciences, Hangzhou Normal University, Hangzhou, China

OPEN ACCESS

Edited by:

Andrea Genre,

University of Turin, Italy

Reviewed by:

Erik Limpens,

Wageningen University, Netherlands

Maria Eugenia Zanetti,

CONICET and Universidad Nacional de La Plata, Argentina

*Correspondence:

Cheniia Shen,

College of Life and Environmental

Sciences, Hangzhou Normal University, 16 Xuelin Street,

Hangzhou 310036, China

shencj@hznu.edu.cn

Specialty section:

This article was submitted to

Plant-Microbe Interaction,

a section of the journal

Frontiers in Plant Science

Received: 19 March 2015

Accepted: 08 June 2015

Published: 19 June 2015

Citation:

Yang Y, Sun T, Xu L, Pi E, Wang S,

Wang $H$ and Shen $C$ (2015)

Genome-wide identification of CAMTA gene family members in Medicago

truncatula and their expression during root nodule symbiosis and hormone treatments. Front. Plant Sci. 6:459. doi: 10.3389/fpls.2015.00459
Calmodulin-binding transcription activators (CAMTAs) are well-characterized calmodulin-binding transcription factors in the plant kingdom. Previous work shows that CAMTAs play important roles in various biological processes including disease resistance, herbivore attack response, and abiotic stress tolerance. However, studies that address the function of CAMTAs during the establishment of symbiosis between legumes and rhizobia are still lacking. This study undertook comprehensive identification and analysis of CAMTA genes using the latest updated $M$. truncatula genome. All the MtCAMTA genes were expressed in a tissues-specific manner and were responsive to environmental stress-related hormones. The expression profiling of MtCAMTA genes during the early phase of Sinorhizobium meliloti infection was also analyzed. Our data showed that the expression of most MtCAMTA genes was suppressed in roots by $S$. meliloti infection. The responsiveness of MtCAMTAs to $S$. meliloti infection indicated that they may function as calcium-regulated transcription factors in the early nodulation signaling pathway. In addition, bioinformatics analysis showed that CAMTA binding sites existed in the promoter regions of various early rhizobial infection response genes, suggesting possible MtCAMTAs-regulated downstream candidate genes during the early phase of $S$. meliloti infection. Taken together, these results provide basic information about MtCAMTAs in the model legume $M$. truncatula, and the involvement of MtCAMTAs in nodule organogenesis. This information furthers our understanding of MtCAMTA protein functions in M. truncatula and opens new avenues for continued research.

Keywords: calcium, CAMTA gene family, Medicago truncatula, Sinorhizobium meliloti infection, nodule formation

\section{Introduction}

$\mathrm{Ca}^{2+}$ signals are core transducers and regulators in many adaptive and developmental plant processes (Kudla et al., 2010). $\mathrm{Ca}^{2+}$ signals are decoded and transmitted by several types of $\mathrm{Ca}^{2+}$ binding proteins that contain a highly conserved $\mathrm{Ca}^{2+}$-binding EF-hand motif (Kudla et al., 2010; $\mathrm{Du}$ et al., 2011). The three main classes of $\mathrm{Ca}^{2+}$ sensors in plants are calmodulins (together 
with calmodulin-like proteins) (CaMs/CMLs), calciumdependent protein kinases (CDPKs), and calcineurin B-like proteins (CBLs) (DeFalco et al., 2010). Calmodulin is the best characterized $\mathrm{Ca}^{2+}$ binding protein whose role relies on its ability to physically bind to a large population of target proteins, including protein kinases, phosphatases, transcription factors, metabolic enzymes, ion channels, transporters, and molecular motors (Yang and Poovaiah, 2003; Bouche' et al., 2005; Du et al., 2011; Poovaiah et al., 2013).

In recent years, over 90 transcription factors have been identified as CaM-binding proteins (CBPs), including CAMTAs (also known as AtSRs), MYBs, WRKY IIDs, bZIPs, CBP60s, NACs, and MADS box proteins (Reddy et al., 2002, 2011; Popescu et al., 2007; Galon et al., 2010a). Calmodulin-binding transcription activators (CAMTAs), the well-studied CaMbinding transcription factors, exist in all multicellular organisms (Bouche' et al., 2002). CAMTAs are characterized by a CG-1 DNA binding domain at the $\mathrm{N}$ terminus, a TIG domain involved in non-specific DNA binding, several Ankyrin repeats responsible for mediating protein-protein interactions, a $\mathrm{Ca}^{2+}$-dependent CaM binding domain (CaMBD), and a varying number of IQ motifs which are $\mathrm{Ca}^{2+}$-independent CaM-binding motifs (Bouche' et al., 2002; Yang and Poovaiah, 2002; Finkler et al., 2007; Du et al., 2009). $\mathrm{Ca}^{2+} /$ calmodulin binds to CAMTAs' CaM binding domain, and this binding regulates the activity of CAMTAs as transcriptional factors (Bouche' et al., 2002; Yang and Poovaiah, 2002; Choi et al., 2005; Du et al., 2009). The CAMTAs can specifically recognize and bind to (A/C/G)CGCG(T/C/G) or (A/C)CGTGT DNA cis-element in the promoter regions of downstream genes, which results in the regulation of gene expression (Yang and Poovaiah, 2002; Choi et al., 2005).

NtER1 from tobacco was the first member of the CAMTA family isolated in a screen for CaM-binding proteins (Yang and Poovaiah, 2000). In Arabidopsis, there are six CAMTAs (AtCAMTA1 to AtCAMTA6), with expressions that are highly responsive to environmental signals such as temperature extremes, UVB, salt, and wounding, as well as hormones such as ethylene, jasmonate acid (JA), abscisic acid (ABA), salicylic acid (SA), and auxin (Reddy et al., 2000; Yang and Poovaiah, 2000, 2002; Galon et al., 2010b). Loss-of-function CAMTA3/AtSR1 mutants showed chlorosis and autonomous lesions, and elevated resistance to pathogens (Galon et al., 2008; Du et al., 2009). These phenotypes were correlated with elevated levels of endogenous SA, suggesting that CAMTA3/AtSR1 was a negative regulator of SA-mediated defense responses (Du et al., 2009). Similarly, the mutant of a rice CAMTA member OsCBT showed significant resistance to pathogens, indicating that OsCBT might also act as a negative regulator on plant defense (Koo et al., 2009). CAMTA3 also played important roles in plant defense against insect herbivore, the regulation of glucose metabolism, and ethylene-induced senescence in Arabidopsis (Laluk et al., 2012; Nie et al., 2012; Qiu et al., 2012). Recently, CAMTA1, CAMTA2, and $C A M T A 3$ were reported to function together in suppressing SA biosynthesis and were involved in freezing tolerance by CBF transcription induction (Doherty et al., 2009; Kim et al., 2013b).

The symbiotic relationships between legume roots and rhizobia bacteria leads to the formation of unique structures called nodules, where the bacteria fix atmospheric dinitrogen into ammonia for plant use. A number of studies suggest that $\mathrm{Ca}^{2+}$ and calmodulin are critical players in plant responses to symbionts (Oldroyd and Downie, 2006; Ranty et al., 2006). In the process of symbiosis establishment, plant roots secrete flavonoids, which stimulate the bacterial synthesis of lipochitooligosaccharide called Nod Factors (NFs) (Denarie et al., 1996; Spaink, 2000). Perception of NFs and rhizobia lead to rapid $\mathrm{Ca}^{2+}$ influx and $\mathrm{Ca}^{2+}$ spiking in legumes and the transduction of Nod factor signal relies on $\mathrm{Ca}^{2+}$ signal transduction (Shaw and Long, 2003; Oldroyd and Downie, 2006; Charpentier and Oldroyd, 2013). A calcium-calmodulin-dependent protein kinase (CCaMK) was shown to be a key decoder of calcium signal and integrally involved in the early events of symbioses (Singh and Parniske, 2012). CCaMK contains three EF hands for calcium binding and a calmodulin-binding domain (Swainsbury et al., 2012). Binding of $\mathrm{Ca}^{2+}$ and $\mathrm{Ca}^{2+} /$ calmodulin inhibits autophosphorylation of CCaMK and activates the protein as protein kinase (Mitra et al., 2004). In early nodulation progress, CCaMK is highly sensitive to changes in calcium levels and regulate expression of various nodule organogenesis genes by phosphorylation and activation of downstream targets as protein kinase (Lévy et al., 2004; Mitra et al., 2004; Swainsbury et al., 2012). CYCLOPS, a DNA-binding transcriptional activator, is a direct phosphorylation substrate of CCaMK (Yano et al., 2008; Singh et al., 2014). The phosphorylation of CYCLOPS activates nodule organogenesis, genes expression and is essential for symbiosis (Singh et al., 2014). Global gene expression profiles in nodules and analysis of Medicago cDNA libraries indicated that several CaM and CaML genes as well as genes encoding calcium and calmodulin binding proteins were found to be expressed in Medicago and Lotus nodules (Fedorova et al., 2002; Colebatch et al., 2004; Moreau et al., 2011). Six M. truncatula CaML proteins were reported to be transferred out of the cytoplasm into the symbiosome space, a matrix-filled space surrounding the bacteroid, and were likely candidates for mediating signal transduction and/or communication between the host plant and microbial symbiont (Liu et al., 2006).

To date, most works on CAMTA genes have focused on Arabidopsis. The expression pattern analysis of CAMTA genes in other plant species may provide preliminary clues on their probable biological functions. CAMTAs from tomato were found to be differentially expressed during fruit development and ripening processes, indicating that calcium signaling is involved in the regulation of fruit development and ripening through calcium/calmodulin/CAMTA interactions (Yang et al., 2012). Very recently, 15 CAMTA genes were identified in soybean (a legume that forms determinate type of nodules), and expression pattern analysis showed that they were responsive to various stresses and hormone signals (Wang et al., 2014). Although this work helped us to gain a preliminary impression of the legume CAMTAs, however, information about CAMTAs in $M$. truncatula which is a model legume that forms indeterminate type of nodules for symbiosis is still lacking. In this study, we report the identification and a comprehensive analysis of the CAMTA gene family in M. truncatula. Specifically, detailed information is provided on the gene structures, chromosomal 
locations, and promoter cis-element identification of seven CAMTA genes in M. truncatula. Tissue-specific expression patterns, responses to hormone treatment, and involvement of MtCAMTA genes in symbiosis were also analyzed. Compared to the previous work which emphasized CAMTAs' response to stress in soybean (Wang et al., 2014), this study is mainly focused on the possible role of MtCAMTA genes in nodulation and symbiosis, and extends the analysis to the transcriptional regulation during early interactions with rhizobium bacteria. The distinct spatiotemporal expression patterns for $M$. truncatula CAMTA genes and their differential responses to rhizobial symbiosis provide basic information about $M$. truncatula CAMTA genes and offer fundamental clues about their involvement in nodule organogenesis.

\section{Materials and Methods}

\section{Plant Material, Growth Conditions, and Hormone Treatment}

M. truncatula cv Jemalong A17 was used throughout the experiment. Seeds were scarified using concentrated sulfuric acid for $10 \mathrm{~min}$, surface sterilized with $6.25 \%(\mathrm{v} / \mathrm{v})$ hypochlorite for $5 \mathrm{~min}$, and washed five times with sterile water. Seeds were germinated on $1 \%$ deionized water agar plates in the dark overnight at $30^{\circ} \mathrm{C}$. After germination, seedlings were grown hydroponically in buffered nodulation medium (BNM) (Engstrom et al., 2002), and the nutrient solution was changed every 3 days. The seedlings were incubated in a growth chamber at a constant $22^{\circ} \mathrm{C}$ over a $16 \mathrm{~h}$ day and $8 \mathrm{~h}$ night with a photon flux density of $100 \mu \mathrm{mol} \mathrm{m} \mathrm{m}^{-2} \mathrm{~s}^{-1}$. For hormone treatment, 14day-old seedlings (10 seedlings) were flood incubated in $1 \mu \mathrm{M}$ indole-3-acetic acid (IAA) (Breakspear et al., 2014), 0.5 mM SA (Palma et al., 2013), $100 \mu \mathrm{M}$ methyl jasmonate (Me-JA) (Zhang et al., 2012), and $100 \mu \mathrm{M}$ ABA (Gimeno-Gilles et al., 2009), respectively. Roots of the hormone-treated and non-treated plants were collected at time intervals of $0,1,6,12$, and $24 \mathrm{~h}$. After collection, all the samples were immediately frozen in liquid nitrogen and stored at $-80^{\circ} \mathrm{C}$ for RNA extraction. Five biological repetitions were used in this experiment.

\section{Identification of Putative MtCAMTA Genes}

Six previously-reported amino acid sequences of Arabidopsis CAMTAs were used as query probes to search the phytozome v10 database (http://phytozome.jgi.doe.gov/pz/portal.html) using the BLAST program. The $e$-value acceptable in the BLAST analysis for CAMTA member identification was "-3." The hidden Markov model (HMM) profiles of the CAMTA protein family (Pfam 03859: CG-1 DNA-binding domain; Pfam 01833: TIG domain; Pfam 12796: ankyrin repeats; Pfam 00612: IQ motifs) were employed to identify MtCAMTA proteins from the hits. All the obtained sequences were sorted as unique sequences for further protein domain search in the Pfam database (http://pfam. xfam.org/). Sequences lacking one or more conserved CAMTA domains were discarded. After correcting from the resulting hits, the remaining non-redundant sequences with the highest similarity to the query sequences were retained as putative MtCAMTA genes.

\section{Gene Structure and Phylogenetic Relationship Analysis}

Genomic, transcript, CDS, and amino acid sequences of MtCAMTA members were downloaded from Phytozome v10 database (http://phytozome.jgi.doe.gov/pz/portal.html). The schematic structures of MtCAMTA members, based on exon/intron data, were analyzed at the Gene Structure Display Server (http://gsds2.cbi.pku.edu.cn/index.php) (Hu et al., 2014). Protein domain structures were analyzed in the Pfam database and a schematic diagram was constructed using Domain Illustrator software (http://dog.biocuckoo.org/) (Ren et al., 2009). The calmodulin binding domain was analyzed in the Calmodulin Target Database (http://www.calmodulin.org/calmodulintarget-database/calmodulin_function/). The Compute $\mathrm{pI} / \mathrm{Mw}$ tool of ExPASy (http://web.expasy.org/compute_pi/) was used to predict molecular weights and isoelectric points of the deduced MtCAMTA proteins. A phylogenetic tree was constructed using MEGA 6.0 software (http://www.megasoftware.net/mega. php) employing the neighbor-joining (NJ) method with 1000 bootstrap replicates.

\section{Analysis of cis-elements}

To investigate cis-elements in the promoter sequences of the MtCAMTA genes, $2 \mathrm{~kb}$ of genomic DNA sequences upstream of the initiation codon (ATG) were obtained from the phytozome v10 database. The putative cis-elements of MtCAMTAs were predicted using the website of plant cis-acting regulatory DNA elements (PLACE) (http://www.dna.affrc.go.jp/PLACE/ signalscan.html).

\section{Bacterial Strains and Rhizobia Infection}

Seven-day-old seedlings were transferred to nitrogen-free BNM medium for an additional 7 days before inoculation with $S$. meliloti strain 1021 (from ATCC database, ATCC ${ }^{\circledR}$ Number: 51124 ). The strain was grown in liquid LBMC medium (Cowie et al., 2006) containing $10 \mathrm{~g} / \mathrm{L}$ tryptone, $5 \mathrm{~g} / \mathrm{L}$ yeast extract, $10 \mathrm{~g} / \mathrm{L}$ $\mathrm{NaCl}, 2.6 \mathrm{mM} \mathrm{MgSO}_{4}, 2.6 \mathrm{mM} \mathrm{CaCl}_{2}$, and supplemented with $200 \mu \mathrm{g} / \mathrm{mL}$ streptomycin at $28^{\circ} \mathrm{C}$ for $48 \mathrm{~h}$. For the inoculations, bacteria were pelleted, washed three times with sterile distilled water and finally diluted in nitrogen-free $B N M$ medium to $\mathrm{OD}_{600}$ of 0.1. For plant inoculation, each seedling was placed in a single $25 \mathrm{ml}$ tube containing the inoculum. For control, the seedlings were treated with nitrogen-free BNM medium only. Roots of the non-inoculated and S. meliloti-inoculated plants were collected at time intervals of $0,1,6,12,24,28$, and $72 \mathrm{~h}$. After collection, all the samples were immediately frozen in liquid nitrogen and stored at $-80^{\circ} \mathrm{C}$ for RNA extraction. Five biological repetitions were used in this experiment. The nodules were harvested at 3 weeks after inoculation and were used for RNA extraction.

\section{RNA Isolation and Quantitative RT-PCR Analysis}

Total RNA from samples was extracted using RNeasy plant mini kits (Qiagen, Hilden, Germany) following the manufacturer's protocol, and digested with DNase I to remove genomic DNA contamination. First strand cDNA was prepared using M-MLV reverse transcriptase (CoWin Biotech, Beijing, China) according 
to the manufacturer's instructions. The gene-specific primers sequences of qRT-PCR were designed using Primer Premier 5 software (PREMIER Biosoft International, Palo Alto, CA) and are shown in Table S1. Triplicate quantitative assays were performed on $1 \mu l$ of each cDNA dilution using SYBR Green Master Mix (CoWin Biotech, Beijing, China) with a MyiQ Single Color Realtime PCR system (Bio-Rad, Hercules, CA, USA), according to the manufacturer's protocol. The procedures for PCR were as follows: $95^{\circ} \mathrm{C}$ for $10 \mathrm{~min} ; 40 \mathrm{cycles}$ of $95^{\circ} \mathrm{C}$ for $15 \mathrm{~s}$, and $60^{\circ} \mathrm{C}$ for $60 \mathrm{~s}$. The expression level of the MtActin (MTR_2g008050) gene was used as the endogenous control to calculate relative fold differences based on comparative cycle threshold $\left(2^{-\Delta \Delta C t}\right)$ values. All the experiments were repeated five times. For data statistical analysis, a given fold change value (two-fold) in the expression levels is used to clarify the significant differences among the control and the treatments.

\section{Results}

\section{Genome-wide Identification of CAMTA Genes in M. truncatula}

A total of seven putative MtCAMTA genes were identified at the phytozome website (http://phytozome.jgi.doe.gov/pz/portal. html). They were named MtCAMTA1 to MtCAMTA7 according to their positions on the $M$. truncatula chromosomes. All of the information on these seven genes, such as gene names, locus IDs, ORF lengths, numbers of introns, locations on chromosome and basic information about deduced polypeptides are provided in Table 1. The predicted MtCAMTA proteins contain 914 (MtCAMTA2) to 1086 (MtCAMTA7) amino-acid residues that are similar to CAMTA members from other organisms (Yang and Poovaiah, 2002; Koo et al., 2009; Yang et al., 2012; Wang et al., 2014). The predicted molecular masses and isoelectric point (pI) range from $103.66 \mathrm{kDa}$ (MtCAMTA2) to $123.62 \mathrm{kDa}$ (MtCAMTA7) and 5.51 (MtCAMTA3) to 7.64 (MtCAMTA5), respectively. Gene structure analysis showed that intron numbers contained in MtCAMTAs range from 11 to 12 (Table 1, Figure 1).

\section{Phylogenetic and Structural Analysis of MtCAMTA Proteins in $M$. truncatula}

The domain structures of MtCAMTA proteins were analyzed in the Pfam database (Punta et al., 2012). MtCAMTA1, 4, 5, and 6 were predicted to contain all the conserved domains of a typical CAMTA protein, including a CG-1 DNA-binding domain (Pfam 03859), a TIG domain involved in non-specific DNA binding (Pfam 01833), several ankyrin repeats (Pfam 12796), one or two IQ motifs which are $\mathrm{Ca}^{2+}$-independent CaM-binding motifs (Pfam 00612), and a $\mathrm{Ca}^{2+}$ dependent calmodulin binding domain (Figure 2). Meanwhile, MtCAMTA 2, 3, and 7 contained all of the conserved domains except for the TIG domain, which is involved in non-specific DNA binding (Figure 2). All of the MtCAMTA proteins were predicted to contain a nuclear localization signal (NLS) in the N-terminus of the protein, consistent with their function in the nucleus as transcription factors (Figure 2).

To investigate the phylogenetic relationships of CAMTA gene families, a phylogenetic tree of CAMTAs from five dicot plants including M. truncatula, Arabidopsis, soybean, tobacco, and tomato was constructed based on neighbor-joining (NJ) methods. Detailed information for these five CAMTA family genes is provided in Table S2. CAMTA gene families were highly conserved among these five dicot plants during the evolutionary process (Figure 3). All of the total 36 proteins from five dicot plants could be clustered distinctly into three groups (group A, B, and C). MtCAMTA1, 4, and 7 were clustered into group A, together with AtCAMTA1, 2, and 3, which have been reported to play important roles in SAmediated defense responses and cold tolerance together in Arabidopsis (Du et al., 2009; Kim et al., 2013a). In addition, six soybean CAMTAs (GmCAMTA1-6), three tomato CAMTAs (SISR1, SISR1L, and SISR4) and NtER1 from tobacco belonged to group A. MtCAMTA3 and MtCAMTA6, AtCAMTA4, SISR2, and SISR2L, and four soybean CAMTAs (GmCAMTA10, 11, 14, and 15) fell into group B. MtCAMTA2 and MtCAMTA5, AtCAMTA5 and AtCAMTA6, SISR3 and SISR3L, and four soybean CAMTAs (GmCAMTA8, 9, 12, and 13) were clustered into group $\mathrm{C}$.

\section{Cis-acting Regulatory Elements in the Promoters OF MtCAMTAs}

Cis-acting regulatory elements are specific motifs existing in the promoter regions of genes functioning as binding sites for transcription factors that regulate gene transcription (Liu et al., 2014). Identification and analysis of cis-acting regulatory

TABLE 1 | CAMTA gene family in Medicago truncatula.

\begin{tabular}{|c|c|c|c|c|c|c|c|c|}
\hline \multirow[t]{2}{*}{ Gene } & \multirow[t]{2}{*}{ Locus ID } & \multirow[t]{2}{*}{ ORF length (bp) } & \multirow[t]{2}{*}{ No. of introns } & \multirow[t]{2}{*}{ Chr. no. } & \multirow[t]{2}{*}{ Chr. location } & \multicolumn{3}{|c|}{ Deduced polypeptide } \\
\hline & & & & & & Length (aa) & Mol wt (kDa) & pl \\
\hline MtCAMTA1 & Medtr2g008840 & 3693 & 11 & 2 & $1646546-1659991$ & 1040 & 116.77 & 5.63 \\
\hline MtCAMTA2 & Medtr2g034650 & 2749 & 12 & 2 & $13256129-13262185$ & 914 & 103.66 & 6.55 \\
\hline MТСАМТАЗ & Medtr3g085050 & 3405 & 11 & 3 & 38424643-38434678 & 958 & 107.84 & 5.51 \\
\hline MtCAMTA4 & Medtr4g094215 & 3093 & 12 & 4 & 37451958-37460364 & 1030 & 115.97 & 5.73 \\
\hline MtCAMTA5 & Medtr4g121840 & 2763 & 12 & 4 & $50265218-50272778$ & 924 & 105.30 & 7.64 \\
\hline MICAMTA6 & Medtr8g080800 & 3123 & 11 & 8 & $34780716-34789253$ & 961 & 107.60 & 5.59 \\
\hline MtCAMTA7 & Medtr8g090205 & 3771 & 11 & 8 & $37838861-37845878$ & 1086 & 123.62 & 5.78 \\
\hline
\end{tabular}




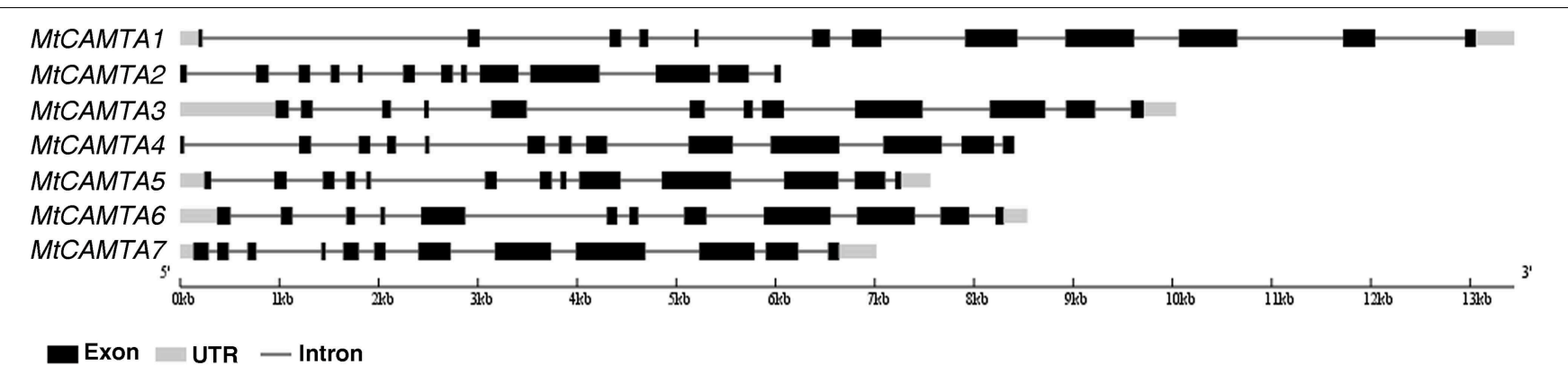

FIGURE 1 | Gene structures of MtCAMTA genes. The exon-intron structures of MtCAMTA genes were determined by comparing the coding Structure Display Server (GSDS, http://gsds.cbi.pku.edu.cn/). The black box sequences and the corresponding genomic sequences using the Gene indicates exons; the gray box indicates $5^{\prime}$ - and $3^{\prime}$-untranslated regions; the black line indicates introns.
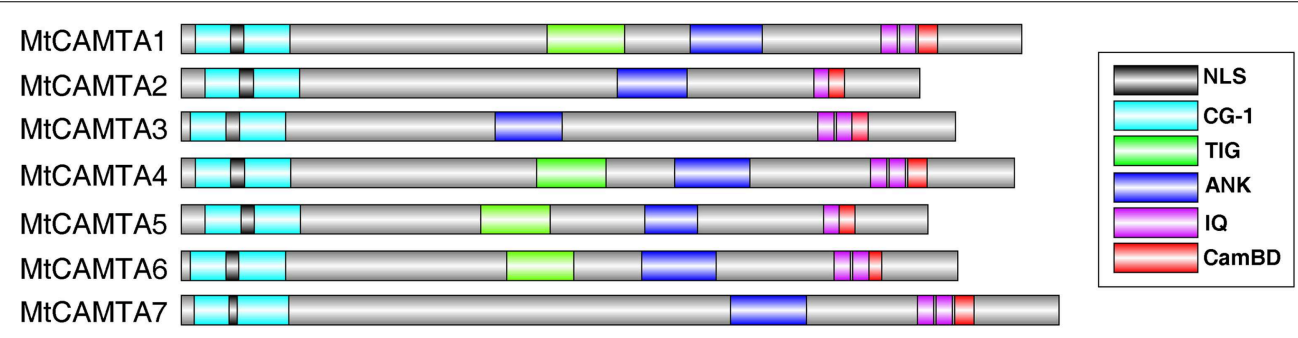

FIGURE 2 | Schematic diagram of the protein domain structures of MtCAMTAs. Analysis of functional conserved domains were performed in the Pfam database (http://pfam.janelia.org/). Nuclear localization signals (NLS) were searched by Motif scan (http://myhits.isb-sib.ch/cgi-bin/ motif_scan). CaM-binding domains (CaMBD) were analyzed in the Calmodulin Target Database (http://calcium.uhnres.utoronto.ca/ctdb/ctdb/).
The domain structures of MtCAMTAs were drawn using Domain Graph software (http://dog.biocuckoo.org/). NLS, Nuclear localization signals; CG-1, CG-1 DNA binding domain; TIG, TIG domain involved in non-specific DNA binding, ANK, Ankyrin repeats responsible for mediating protein-protein interactions; IQ, $\mathrm{Ca}^{2+}$-independent CaM-binding IQ motifs, CamBD, $\mathrm{Ca}^{2+}$-dependent CaM binding domain. elements present in the promoters of these genes help to expand our current understanding of the molecular regulation of these genes. We researched the $-2000 \mathrm{bp}$ upstream promoter regions of the seven $M t C A M T A$ genes for several well-studied stresses/stimuli response cis-acting elements. Seven cis-elements were used in this study: ABA-responsive element (ABRE: C/TACGTGG/T) (Osakabe et al., 2014), SA-responsive promoter element (SARE: TGACG) (Pieterse and Van Loon, 2004), environmental signal response element (G-box: CACGTG) (Williams et al., 1992), WRKY binding site (W-box: TTGACC/T) (Chen et al., 2012), phosphate starvation-responsive element (P1BS: GNATATNC) (Rubio et al., 2001), sulfur-responsive element (SURE: GAGAC) (Maruyama-Nakashita et al., 2005), and the CAMTA binding site (CG-box) (Yang and Poovaiah, 2002; Choi et al., 2005).

The results showed that there were various known stresses/stimuli-related cis-acting elements that existed in the promoter regions of seven MtCAMTAs (Table 2). The upstream flanking regions of MtCAMTA4 contained five types of cis-elements including ABRE, SARE, G-box, W-box, and CG-box. The upstream flanking region of MtCAMTA1 and MtCAMTA6 each had four types of stresses/stimuli-related cis-elements. MtCAMTA1 contained ABRE, G-box, W-box, and SURE cis-elements in the promoter region, and the number of $\mathrm{W}$-box reached five, indicating a possible transcriptional regulation by WRKY transcription factors. MtCAMTA6 had SARE, G-box, CG-box, and P1BS cis-elements in the promoter regions. Three W-box, two CG-box and one P1BS were located on the promoter of MtCAMTA7, indicating transcriptional regulation by WRKY transcription factors and by the CAMTAs themselves. Two SARE and one CG-box were found in the promoter of MtCAMTA2. The promoter region of MtCAMTA3 contained only one P1BS. Meanwhile, MtCAMTA5 did not contain any chosen cis-element in its promoter region except for one CG-box.

\section{Tissue-specific Expression Patterns of MtCAMTA Genes}

To elucidate the possible functions of the MtCAMTA genes, their expression profiles were investigated by $\mathrm{qRT}-\mathrm{PCR}$ in different tissues or organs, including the cotyledons from 1-week-old seedlings, leaves, roots, stems of 2 -week-old seedlings, and the flowers from 2-month-old plants. As a result, transcripts of the seven MtCAMTA genes could be detected in all of the different tissues or organs, and their expression varied among tissues (Figure 4). The transcript levels of all the six MtCAMTA genes, except for MtCAMTA3, were highest in roots compared to other organs, while MtCAMTA3 was mainly expressed in cotyledons, leaves, and flowers. Furthermore, RNA abundances of three $M t C A M T A$ genes from group A (MtCAMTA1, 4, and 7) in roots 


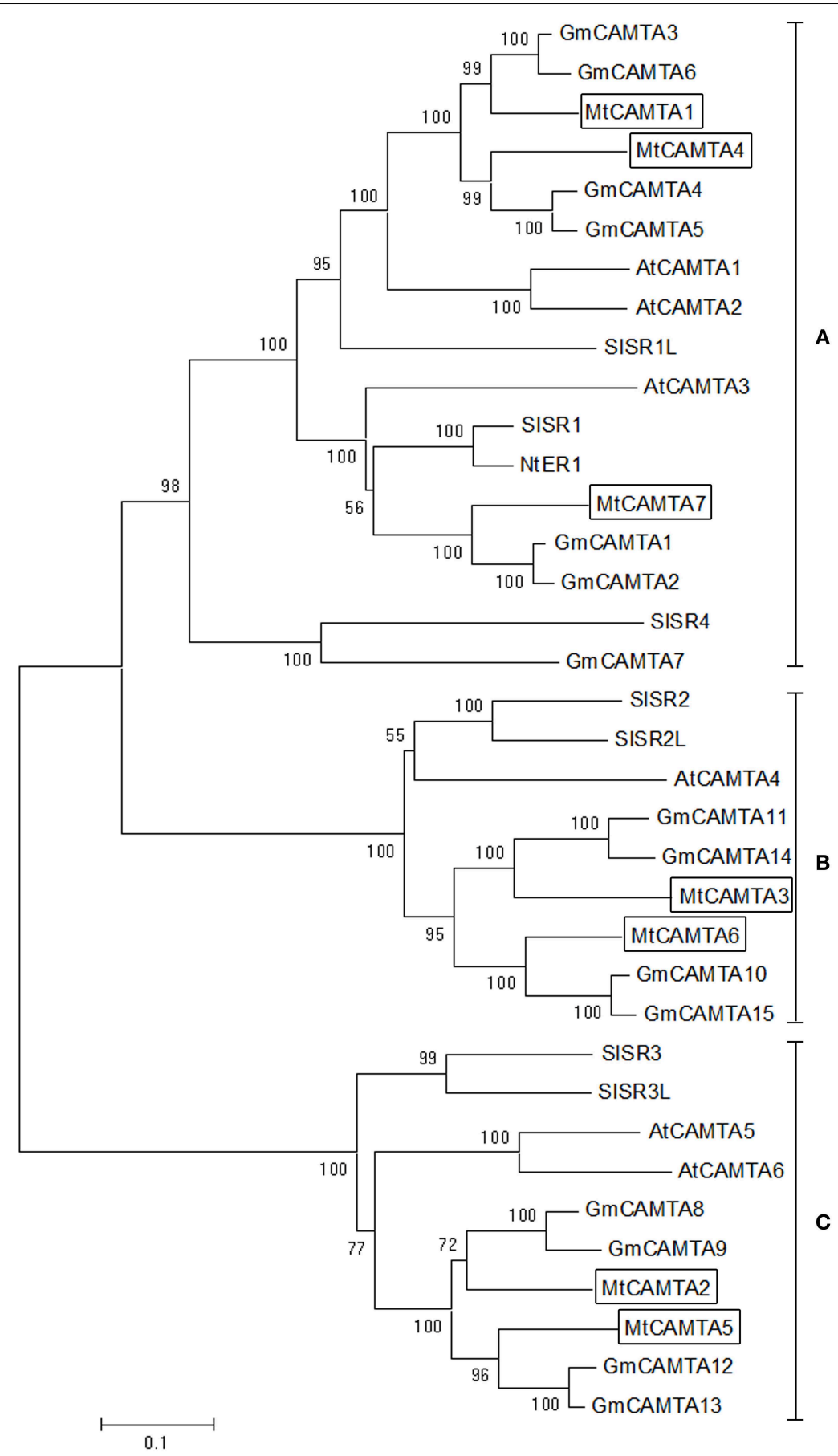

FIGURE 3 | Phylogenetic tree of CAMTA homologs from dicot plants. Phylogenetic trees of CAMTAs from five dicot plants, including M. truncatula, Arabidopsis, soybean, tobacco, and tomato, were generated using the MEGA6 program by neighbor-joining analysis. Bootstrap values are displayed on the branches. The seven MtCAMTA proteins are boxed. The corresponding locus ID or NCBI GenBank accession numbers of CAMTAs from five dicot plants are shown in Table S2. were generally higher than genes from groups $\mathrm{B}$ and $\mathrm{C}$ in all other tissues.

Since the gene expression profiles for the majority of M. truncatula genes are available in the Medicago gene atlas (MtGEA, http://mtgea.noble.org/v3/), the expression data of MtCAMTA genes in different tissues were also searched and analyzed in the MtGEA (Benedito et al., 2008). The probeset ID of MtCAMTA genes has been 
TABLE 2 | Numbers of stress-related cis-elements in the upstream 2 kb regions of MtCAMTA genes.

\begin{tabular}{lccccccc}
\hline & ABRE & SARE & $\begin{array}{c}\text { G- } \\
\text { box }\end{array}$ & $\begin{array}{c}\text { W- } \\
\text { box }\end{array}$ & $\begin{array}{c}\text { CG- } \\
\text { box }\end{array}$ & P1BS & SURE \\
\hline MtCAMTA1 & 1 & 0 & 1 & 5 & 0 & 0 & 2 \\
MtCAMTA2 & 0 & 0 & 0 & 0 & 1 & 0 & 2 \\
MtCAMTA3 & 0 & 0 & 0 & 0 & 0 & 1 & 0 \\
MtCAMTA4 & 2 & 1 & 2 & 2 & 3 & 0 & 0 \\
MtCAMTA5 & 0 & 0 & 0 & 0 & 1 & 0 & 0 \\
MtCAMTA6 & 0 & 2 & 1 & 0 & 1 & 2 & 0 \\
MtCAMTA7 & 0 & 0 & 0 & 3 & 2 & 1 & 0 \\
\hline
\end{tabular}

ABRE, ABA-responsive element; SARE, SA-responsive promoter element; G-box, environmental signal response element; $W$-box, WRKY binding site; P1BS, phosphate starvation-responsive element; SURE, sulfur-responsive element; CG-box, the CAMTA binding site.

listed in Table S3. Generally, these data showed the similar tissue-specific expression pattern for MtCAMTA genes (Figure S1).

\section{Expression Profiles of MtCAMTA Genes during the Early Phase of Sinorhizobium meliloti Infection}

Changes in intracellular $\mathrm{Ca}^{2+}$ signaling are well-documented features of legume-rhizobia interactions and nodule development (Lévy et al., 2004). During nodule formation, $\mathrm{Ca}^{2+}$ and calmodulin are critical players in plant responses to symbionts (Oldroyd and Downie, 2006; Ranty et al., 2006). In this study, we were interested in the putative roles of MtCAMTAs as calcium/calmodulin regulated transcription factors during nodule formation in M. truncatula, and we made our preliminary efforts to explore the involvement of MtCAMTAs during this process.

To investigate the expression responses of MtCAMTA genes during the early phase of $S$. meliloti infection, qRT-PCR was used to detect the expression of MtCAMTA genes under S. meliloti infection. Surprisingly, the expression levels of almost all the $M t C A M T A$ genes showed a drastic decline during the early phase of $S$. meliloti infection in the roots, except for MtCAMTA3, which showed no detectable changes in the $72 \mathrm{~h}$ monitored period after $S$. meliloti infection (Figure 5). After $24 \mathrm{~h}$ infection, MtCAMTA4 and MtCAMTA5 reached a maximum repression of 5-10 folds. Meanwhile, MtCAMTA1, 2, 6, and 7 reached a maximum repression after $48 \mathrm{~h}$ infection. These results showed that the expression of six MtCAMTAs were responsive to early $S$. meliloti infection. The expression levels of $M$. truncatula early nodulin gene $M t E N O D 11$, used as a positive control, were also detected (Journet et al., 2001). The result showed that MtENOD11 was strongly and rapidly induced during the early phase of $S$. meliloti infection (Figure S2).

In addition, the expression data of MtCAMTA genes under S. meliloti infection and nod factor treatment was searched and analyzed in the MtGEA (Czaja et al., 2012; Breakspear et al., 2014). The expression levels of MtCAMTA genes in root hairs showed no evident changes during the early phase of $S$. meliloti infection (Figure S3). Also, the expression levels of most MtCAMTA genes only slightly declined after $24 \mathrm{~h}$ nod factor treatment (Figure S3). As calcium spiking is also a key response to arbuscular mycorrhizal infection, the expression pattern of MtCAMTA genes under AM fungal signals Myc-LCOs treatment was also investigated in the MtGEA (Czaja et al., 2012). The expression levels of MtCAMTA genes showed no detectable changes under 6 and $24 \mathrm{~h}$ Myc-LCOs treatment in WT roots (Figure S3). However, the expression of all the MtCAMTA genes were suppressed after 6 and $24 \mathrm{~h}$ Myc-LCOs treatment in $d m i 3$ mutant roots (Figure S3).

\section{Analysis of the CAMTA Binding Sites in the Promoter Region of Rhizobial Infection Response Genes}

Transcriptomics approaches have been used in M. truncatula and Lotus japonicus to obtain a view of the range of genes associated with early or late stages of nodulation (Fedorova et al., 2002; Colebatch et al., 2004; Lohar et al., 2006; Molesini et al., 2014). In $M$. truncatula, hundreds of plant genes involved in early stages of $S$. meliloti infection were identified using a microarray with about $6000 \mathrm{cDNAs}$ (Lohar et al., 2006). We screened these genes and chose those with an expression ratio up to 2.5fold. Then the CAMTA binding sites (A/C/G)CGCG(T/C/G) or (A/C)CGTGT DNA were analyzed in the promoter regions of these genes. Interestingly, about $45 \%$ of these early rhizobial infection response genes (73/162) contained CAMTA binding sites (Table S3), while the proportion for a random selection of genes with similar numbers was about 36\%. These genes encode proteins involved in calcium transport and binding, reactive oxygen metabolism, cell proliferation, defense response and cytoskeleton and cell wall functions, and represent possible candidates for MtCAMTA-regulated downstream genes during the early phase of $S$. meliloti infection.

The CAMTA binding sites overlap with the ABA-responsive element, which is partly contained within in the CAMTA site (Kaplan et al., 2006). The ABA-responsive elements were also analyzed in the promoter regions of the infection regulated genes containing the CAMTA binding sites. A few of these genes contained the ABA-responsive elements in their promoter regions (Table S4). This result indicated that competition may exist between CAMTA binding and the ABA response for these infection regulated genes.

\section{Expression Patterns of MtCAMTA Genes in Nodules}

To investigate whether the MtCAMTA genes were expressed in nodules, qRT-PCR analysis was performed using total RNA from nodules. Transcripts of all the seven MtCAMTA genes could be detected in nodules, although the expression level of each gene varied in nodules (Figure 4). The expression levels of $M t C A M T A 1$ and MtCAMTA7 in nodules were highest compared to other genes. MtCAMTA4, which was predominantly expressed in the roots, was rarely expressed in nodules.

Recently, laser-capture microdissection (LCM) has been successfully used in $M$. truncatula to precisely analyze gene expression in different zones of the nodules (Limpens et al., 2013; 


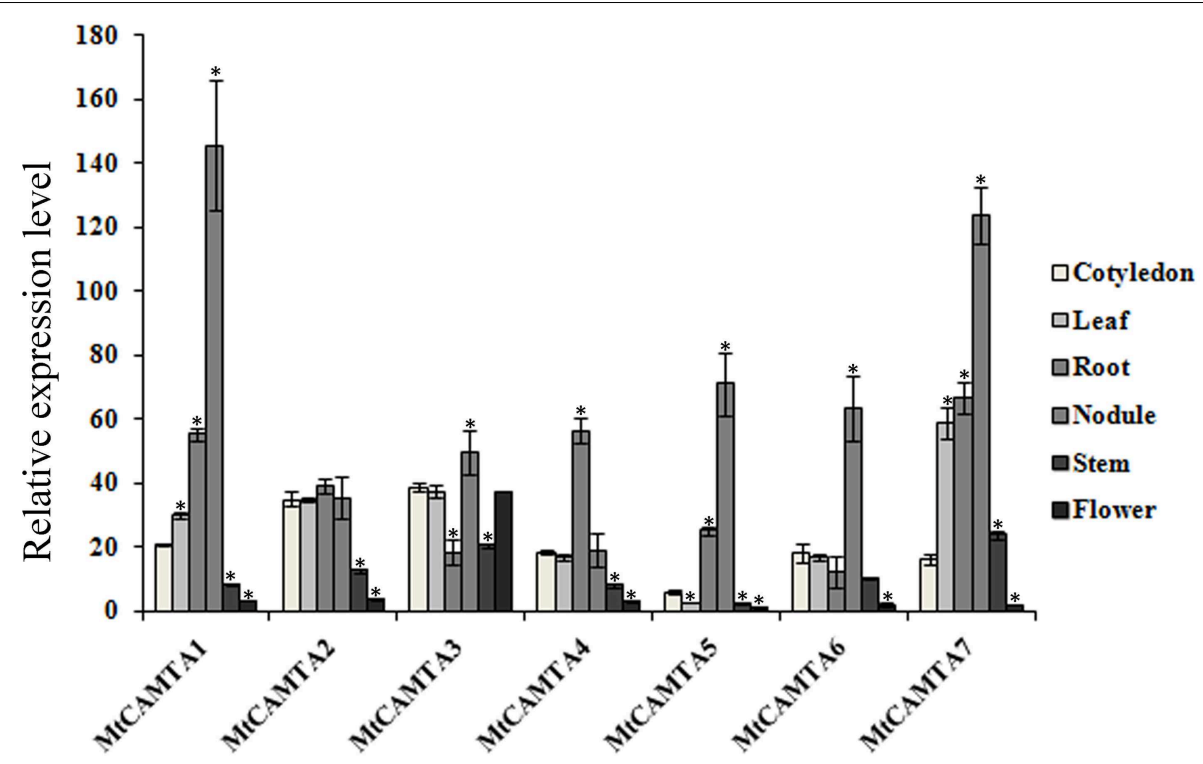

FIGURE 4 | Tissue-specific expression patterns of MtCAMTA genes. Expression patterns of the MtCAMTA genes in five indicated tissues were analyzed by qRT-PCR. Relative expression was calculated based on the expression level of the target gene vs. the level of internal control gene
MtACTIN, which was set to 1000. Each bar represents the mean of five biological replications with standard error. Asterisk denotes significance at $P<0.05$ (Student's $t$-test) compared with the expression level of MtCAMTA genes in cotyledon.

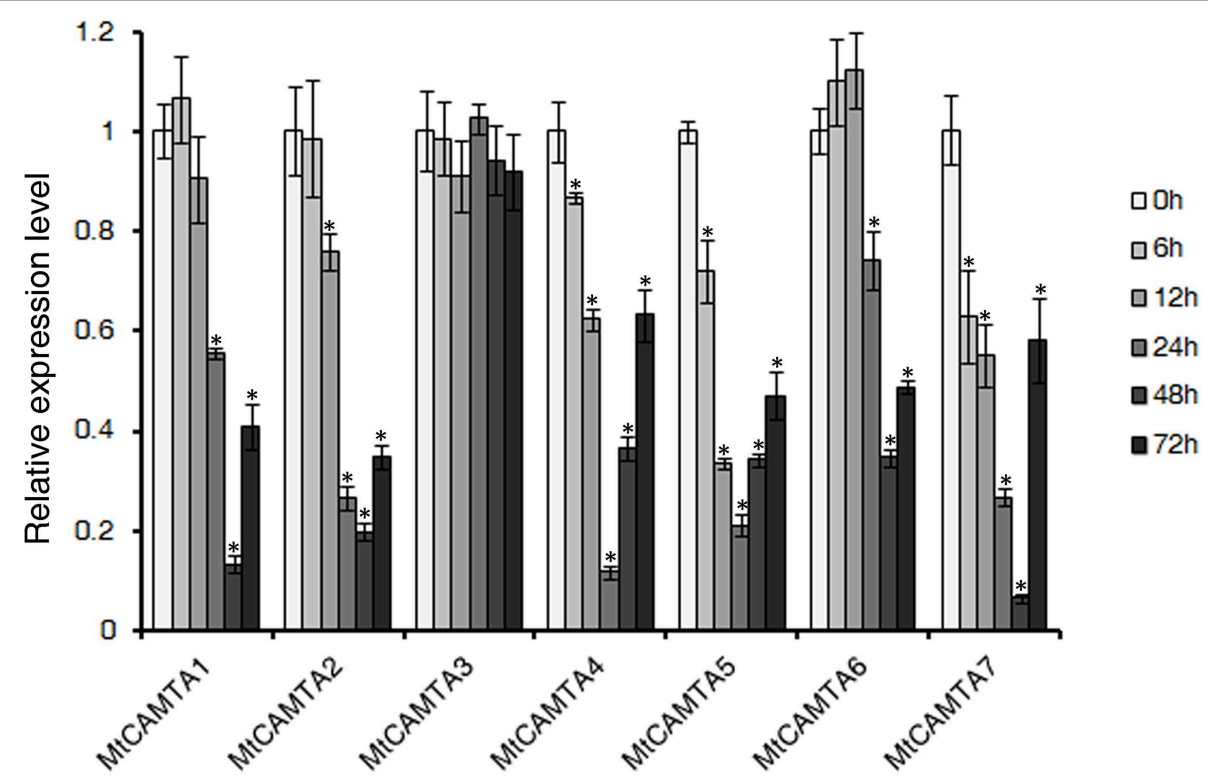

FIGURE 5 | Expression profile of MtCAMTA genes during the early phase of $\mathbf{S}$. meliloti infection. The expression levels of the MtCAMTA genes were analyzed by qRT-PCR at different time points (6/12/24/48/72 hpi) after S. meliloti infection. The expression levels of MtCAMTA genes in uninfected seedlings were normalized to a value of 1. Each bar represents the mean of five biological replications with standard error. Asterisk denotes significance at $P<0.05$ (Student's $t$-test) compared with the expression levels of MtCAMTA genes in uninfected seedlings.
Roux et al., 2014). Specifically, expression data of MtCAMTA genes in different zones of the nodules were collected and analyzed based on the RNA sequencing coupling LCM resource (Table S5, Roux et al., 2014). In general, the seven MtCAMTA genes were expressed in all the five different zones of nodules, although the expression levels in each zone were different.
MtCAMTA2, 6, and 7 were predominantly expressed in the meristematic zone, while both MtCAMTA2 and 6 were rarely expressed in the proximal infection zone. The expression of MtCAMTA5 was enriched in the meristematic zone and the distal infection zone, while the expression was very low in the inter zone. MtCAMTA1, 3, and 4 were equally expressed in the five 
zones of nodules, although slight differences existed. Data from Erik Limpens study also showed the similar results (Limpens et al., 2013).

\section{Expression of MtCAMTA Genes in Response to Hormone Treatments}

It has been reported that CAMTA genes in Arabidopsis and soybean respond to various plant hormones, such as auxin, ABA, SA, and JA (Yang and Poovaiah, 2002; Galon et al., 2010b; Wang et al., 2014). Additionally, hormones such as auxin, SA, JA, and ABA act as positive or negative regulators of nodulation organogenesis and play central roles in coordinating plant responses to rhizobium infection (Suzuki et al., 2004; Stacey et al., 2006; Sun et al., 2006; Oldroyd and Downie, 2008). Here, the expressions of MtCAMTA genes in response to IAA, ABA, SA, and JA stresses were tested. As show in Figure 6A, all the $M t C A M T A$ genes were reduced in the root under IAA treatment, except for MtCAMTA7, which showed no detectable changes. For SA treatment, all the MtCAMTA genes were induced quickly after $1 \mathrm{~h}$ treatment, and reached a peak after 6 or $12 \mathrm{~h}$ treatment (Figure 6B). The expression of MtCAMTA5 and 6 showed a dramatic increase after SA treatment, while MtCAMTA3 was slightly induced by SA treatment (Figure 6B). Under JA treatment, the expression of
MtCAMTA1, 4, 5, and 6 were considerably induced, and reached a maximum fold after 6 to $12 \mathrm{~h}$ treatment (Figure 6C). For ABA treatment, only MtCAMTA7 was induced, and the expression level reached the maximum under $12 \mathrm{~h}$ treatment; while the expression of MtCAMTA1 and 6 were suppressed by ABA treatment (Figure 6D). The results suggested that the expression of MtCAMTA genes responded to the four nodulation-regulated and stress-related hormones, including IAA, ABA, SA, and JA.

Considering the close relationship of SA, JA, and pathogens, it is interesting to investigate whether MtCAMTA genes were responsive to pathogens infection. Here, a preliminary investigation was undertaken to gain some insight. The expression data of MtCAMTA family genes during infection with the three pathogens in the MtGEA database were analyzed. The result showed that MtCAMTA genes were differentially responsive to Ralstonia solanacearum and Phymatotrichum Root Rot infection, while no detectable expression changes occurred in response to Macrophomina phaseolina infection (Figure S4).

\section{Discussion}

CAMTA transcription factors are important players in the calcium/calmodulin transduction signal pathway. So far, the features and functions of CAMTA family genes have already been
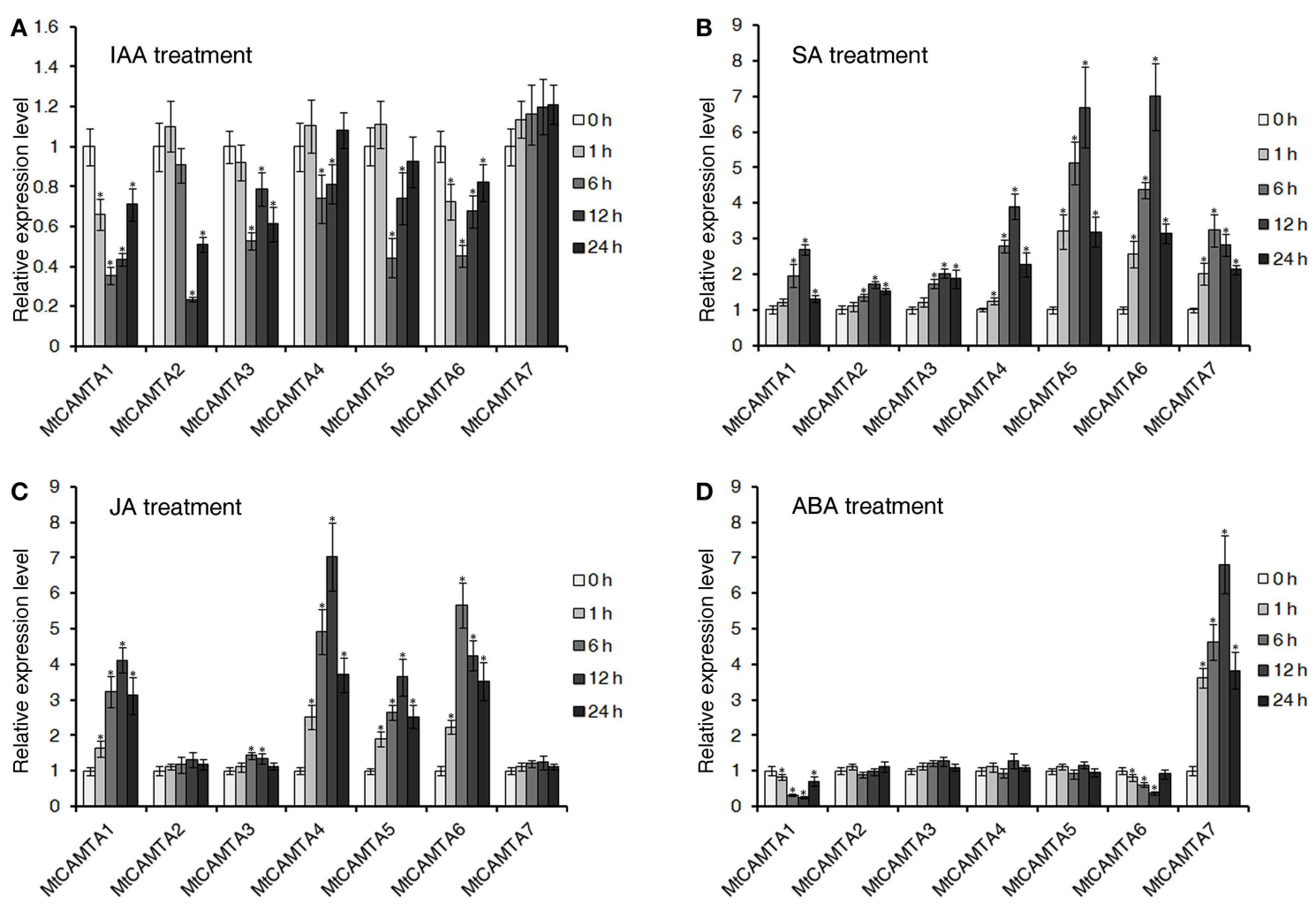

FIGURE 6 | Expression of MtCAMTAs in response to IAA, SA, JA, and $A B A$ treatments. Two-week-old $M$. truncatula seedlings were treated with $1 \mu \mathrm{M}$ IAA (A), $0.5 \mathrm{mM}$ SA (B), $100 \mu \mathrm{M} \mathrm{Me-JA} \mathrm{(C),} \mathrm{and}$ $100 \mu \mathrm{M}$ ABA (D). The expression of seven MtCAMTA genes were analyzed by qRT-PCR in roots of hormone-treated and none-treated

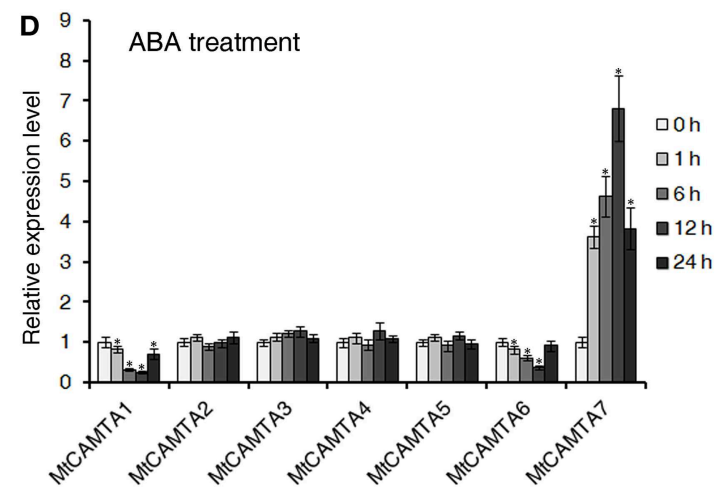

seedlings. The expression levels of MtCAMTA genes in none-treated seedlings were normalized to a value of 1 . Each bar represents the mean of five biological replications with standard error. Asterisk denotes significance at $P<0.05$ (Student's $t$-test) compared with the expression levels of MtCAMTA genes in none-treated seedlings. 
investigated and identified in several plant species, including Arabidopsis, tomato, tobacco, soybean, and rice (Yang and Poovaiah, 2002; Du et al., 2009; Koo et al., 2009; Yang et al., 2012; Wang et al., 2014). However, to date there are still no studies on CAMTAs in M. truncatula, an important leguminous model plant that is widely used in symbiosis research. Genome-wide analysis of the CAMTA genes in M. truncatula would facilitate a better understanding of the role of this gene family during nodule formation.

\section{Characterization and Expression Patterns of the MtCAMTA Gene Family in Medicago truncatula}

In this study, seven members of $M$. truncatula CAMTA family genes were identified. The number of $M$. truncatula CAMTA genes was similar to Arabidopsis (six members) and much smaller than soybean (15 members), although the Medicago genome size is approximately three times that of the Arabidopsis genome and half of the soybean genome (Young et al., 2011). The higher number of soybean CAMTA genes may be explained by the allotetraploid nature of soybean.

Similar to all of the CAMTAs that have been characterized in various species, all of the seven family members contain conserved domains of CAMTAs (Figure 2). A combined N-J tree was also constructed to investigate the phylogenetic relationships of CAMTA genes in plants and their evolutionary relationships. Based on the phylogenetic tree, we found a close relationship exists among CAMTAs in five dicot plants, suggesting that the functions of MtCAMTAs could be similar to CAMTAs in other plant species (Figure 3). Interestingly, three members of the CAMTAs gene family (MtCAMTA1, 4, and 7) showed a close relationship with three Arabidopsis CAMTA genes (AtCAMTA1, 2 , and 3) that have been well-studied and are known to participate together in SA-mediated defense responses and cold tolerance (Doherty et al., 2009; Kim et al., 2013b). These results indicate that MtCAMTA1, 4, and 7 have a close relationship with each other and may function together in the same pathway as homolog genes. The expression patterns of CAMTAs in different groups from three different species (including Arabidopsis, $M$. truncatula, and soybean) were compared under hormones treatment. Most of the CAMTA members from group A were induced by $\mathrm{SA}, \mathrm{JA}$, and $\mathrm{ABA}$ treatment. For group $\mathrm{B}$, all the CAMTAs in this group were induced by SA; most of them were induced by JA; while most of them were not induced and even repressed under ABA treatment. Most of the CAMTA members from group $C$ were induced by $S A$ and JA; for ABA treatment, the expression of AtCAMTAs and GmCAMTAs were up-regulated, while there was no detectable expression changes for the two MtCAMTAs. This results indicated that CAMTAs from each group may have distinctive expression patterns under hormones treatment.

The tissue-specific expression analysis of MtCAMTA genes showed differential expression in various $M$. truncatula tissues and organs (Figure 4). The different expression patterns of MtCAMTA genes suggested that they may play different roles in plant growth and development. In particular, six genes are mainly expressed in the root. This root-preferential expression type indicated a possible role of MtCAMTA genes in response to environmental stimuli and bacterial infection in soil. The expression levels of MtCAMTA1, 4, and 7 in roots were higher than the other four genes in any tissue, emphasizing their important role in root growth in M. truncatula.

As signal response genes, CAMTAs were reported to be responsive to diverse stresses and stimuli in Arabidopsis, tomato, and soybean (Yang and Poovaiah, 2000; Galon et al., 2010b; Yang et al., 2012; Wang et al., 2014). Enrichment of cis-elements involved in stresses/stimuli response in MtCAMTA promoters suggest that they are likely to respond differently to various stresses and stimuli signals, like other CAMTAs in different species. The enrichment of the CG-box in the promoter regions of most MtCAMTA family members suggested comprehensive transcriptional regulation by the CAMTAs themselves, and indicated a complicated regulation network between them.

\section{The Putative Function of MtCAMTAs in Nodule Formation during the Early Phase of Sinorhizobium meliloti Infection}

During nodule formation, calcium plays an essential role as a secondary messenger. It is convinced that CCaMK is a key calcium sensor in the early nodulation signaling pathway (Mitra et al., 2004). After binding to $\mathrm{Ca}^{2+}$ or $\mathrm{Ca}^{2+} /$ calmodulin, CCaMK induces the epidermal expression of specific early nodulation genes via the phosphorylation of transcription factors like CYCLOPS (Lévy et al., 2004; Mitra et al., 2004; Yano et al., 2008; Singh and Parniske, 2012; Singh et al., 2014). Apart from CCaMK, several CaM, CML genes and calcium/calmodulin binding proteins were also found to be expressed in Medicago and Lotus nodules by expression profile analysis (Fedorova et al., 2002; Colebatch et al., 2004; Moreau et al., 2011). However, with the exception of CCaMK, a well-known important regulator of plant-microbe symbioses, the role of $\mathrm{Ca}^{2+}$ in fully developed nodules was less clear. The involvement of other players in the calcium signal transduction pathway of symbiosis is still largely unknown and needs further research. Our results showed that the expression levels of MtCAMTA genes responded to $S$. meliloti infection in M. truncatula. The expression of all but one MtCAMTA genes were dramatically suppressed during $S$. meliloti infection (Figure 5). This expression pattern indicated that MtCAMTAs may be involved in the transduction of the early nodulation signal as calcium regulated transcription factor in symbiosis. To date, several important transcription factors have been found to play important roles in symbiosis, including CYCLOPS, NIN, NF-Y, NSPs, SIP1, and IPN2, which was reported most recently (Soyano and Hayashi, 2014). However, there is no report about the involvement of CaM-binding transcription factors in symbiosis. This study showed that the MtCAMTA gene family may be a novel CaM-binding transcription factor family involved in the early phase of infection.

Previous work has shown that CAMTAs can act as either positive or negative regulators after binding to calcium/calmodulin (Du et al., 2009; Nie et al., 2012; Kim et al., 2013b). Based on cis-elements analysis, we found that most of the nodulation genes that are up-regulated or down-regulated during the early phase of $S$. meliloti infection contained the 
CAMTA binding site in their promoter regions (Table S4). This result indicated that MtCAMTAs can possibly bind to the nodulation genes and regulate their expression as transcription factors. Therefore, it can be inferred that calcium can regulate the nodulation signaling pathway by forming a calcium/calmodulin complex to activate MtCAMTAs, which then modulate the expressions of downstream genes associated in the nodulation signaling pathway positively or negatively as transcription factors. Considering the early down-regulation of CAMTA genes during rhizobial infection, it can be inferred that these factors need to be down-regulated to allow infection and they may be negative regulators of infection. However, this presumption still needs to be confirmed, and the candidate downstream regulated genes should be screened by further investigation.

During the early stages of $M$. truncatula infection, the morphology of the root hairs changed, including swelling of root hair tips by $1 \mathrm{hpi}$, the asymmetrical root hair tip by $6 \mathrm{hpi}$, hair branching by $12 \mathrm{hpi}$, and curled root hairs by $24 \mathrm{hpi}$ (Lohar et al., 2006). Inner cortical cells started dividing between 24 and $48 \mathrm{hpi}$, and the infection threads initiated in the tightly curled root hairs by $48 \mathrm{hpi}$ (Lohar et al., 2006). At $72 \mathrm{hpi}$, infection threads penetrated the cortical cells and nodule primordia were observed (Lohar et al., 2006). During the early phase of infection, the expression levels of all the MtCAMTA genes, with the exception of MtCAMTA3, showed a drastic decline, and reached a maximum fold of repression after 24 or $48 \mathrm{~h}$ infection (Figure 5). In addition, microarray data from the MtGEA also showed that no evident changes occurred for MtCAMTA genes in root hairs during the early phase of $S$. meliloti infection (Figure S3). Thus, it can be inferred that the down-regulation of MtCAMTA genes may be needed mainly in the phase of inner cortical cells dividing. However, further investigation should be undertaken to confirm this presumption.

Our results showed that all the seven MtCAMTAs were expressed in nodules, although the expression level of each gene varied in nodules (Figure 4). This result indicates that the seven MtCAMTA genes may be involved in nodule morphogenesis. Based on the RNA sequencing coupling LCM resource, we also found that the expression levels of MtCAMTAs in each zone of the nodules were different, indicating that they may play different roles in the different stages of nodule morphogenesis. Furthermore, we took advantage of the microarray data (GPL4592) to investigate the expression pattern of CAMTA gene in another legume model plant (soybean). The data showed that the expression of most CAMTA genes is down-regulated in the roots with nodules compared to the roots used as control (Figure S5, Table S6). It suggested that the down-regulation of CAMTA genes may be conserved in legume.

\section{MtCAMTA Genes were Responsive to Hormones which had Critical roles in the Regulation of Nodule Organogenesis}

The involvement of CAMTA genes in response to plant hormones has been well-studied in Arabidopsis and soybean (Yang and Poovaiah, 2002; Galon et al., 2010b; Wang et al., 2014). Previous studies indicated that four Arabidopsis CAMTA genes were quickly induced by ABA and SA treatment (Yang and Poovaiah,
2002). AtCAMTA1 was induced by endogenous auxin, and has a possible role in auxin signaling (Galon et al., 2010b). Recently, 15 soybean CAMTA genes were identified, and their expression was responsive to three major stress-related hormones, including ABA, SA, and JA (Wang et al., 2014). Our investigation on the response of MtCAMTAs to four major stress-related hormones came to a similar conclusion. The expressions of most MtCAMTA genes were responsive to the four hormones, including IAA, SA, $\mathrm{JA}$, and $\mathrm{ABA}$ (Figure 6).

Plant hormones play critical roles in the regulation of nodule organogenesis in legumes (Hirsch and Fang, 1994; Oldroyd and Downie, 2008). Auxin was reported to act as positive regulator in nodulation initiation in M. truncatula roots (Oldroyd and Downie, 2008). Inhibition of auxin polar transport at the nodule site could precede the earliest stages of root nodule formation in legumes (Mathesius et al., 1998). High levels of endogenous auxin have been correlated with increased numbers of nodules, while reduction of auxin levels in the root inhibits further nodule initiation in M. truncatula (van Noorden et al., 2006). Our data showed that the expression of almost all of the MtCAMTA family members was repressed by auxin treatment (Figure 6A). Interestingly, this result correlated with the expression inhibition of MtCAMTA genes by S. meliloti treatment (Figure 5).

In contrast to auxin, three major stress-related hormones $\mathrm{SA}$, $\mathrm{JA}$, and $\mathrm{ABA}$ all act as negative regulators to repress nodulation (Hirsch and Fang, 1994; van Noorden et al., 2006). Reduction of endogenous SA levels elevated the number of infections and the mean nodule number in both L. japonicus and M. truncatula plants (Stacey et al., 2006). JA suppressed the early stages of nodulation by inhibiting Nod factor-induced calcium spiking and calcium oscillations (Nakagawa and Kawaguchi, 2006; Sun et al., 2006). Exogenous ABA blocked the step between root hair swelling and curling during nodule initiation, and inhibited root nodule formation after inoculation with rhizobia (Suzuki et al., 2004). Our investigation showed that while under these three nodulation-negative-regulated hormones treatment, most of the MtCAMTA family members were induced (Figures 6B-D). The expression of most MtCAMTA genes was significantly induced (greater than four-fold), with SA and JA treatments. These results may indicate a complicated relationship between hormone regulation and expression of MtCAMTA family members in nodule formation. Under hormones treatment, most of MtCAMTAs were induced or repressed, and reached the maximum level after 6 or $12 \mathrm{~h}$ treatment (Figure 6). Compared to the repression of CAMTAs during infection, their expressions reached the maximum fold earlier under hormones treatment. It can be assumed that auxin inhibits the expression of MtCAMTA genes during the early phase of infection, thus promoting the process of nodulation. whereas $\mathrm{SA}, \mathrm{JA}$, and $\mathrm{ABA}$ may induce MtCAMTA genes to repress nodulation.

$M$. truncatula is an important leguminous model plant that is widely used in studies of symbiotic association with $\mathrm{N}$-fixing bacteria. The present study has identified and characterized all of the CAMTA genes in M. truncatula. The identification, chromosomal location, protein domain, and expression profiling analysis of MtCAMTA genes in different tissues were all investigated in detail. Expression profile analysis of MtCAMTAs 
during early nodulation process indicated that CAMTAs in $M$. truncatula may be important transcription factors during the early phase of $S$. meliloti infection. These results should provide a solid foundation for future functional studies and also in guiding subsequent experimental work on CAMTA genes in this model species.

\section{Acknowledgments}

This study was funded by the Zhejiang Provincial Natural Science Foundation of China under Grant No. LQ14C020002

\section{References}

Benedito, V. A.,Torres-Jerez, I., Murray, J. D., Andriankaja, A., Allen, S.,Kakar, K., et al. (2008). A gene expression atlas of the model legume Medicago truncatula. Plant J. 55, 504-513. doi: 10.1111/j.1365-313X.2008.03519.x

Bouche', N., Scharlat, A., Snedden, W., Bouchez, D., and Fromm, H. (2002). A novel family of calmodulin-binding transcription activators in multicellular organisms. J. Biol. Chem. 277, 21851-21861. doi: 10.1074/jbc.M200268200

Bouche', N., Yellin, A., Snedden, W. A., and Fromm, H. (2005). Plant-specific calmodulin-binding proteins. Annu. Rev. Plant Biol. 56, 435-466. doi: 10.1146/annurev.arplant.56.032604.144224

Breakspear, A., Liu, C., Roy, S., Stacey, N., Rogers, C., Trick, M., et al. (2014). The root hair "infectome" of Medicago truncatula uncovers changes in cell cycle genes and reveals a requirement for Auxin signaling in rhizobial infection. Plant Cell 26, 4680-4701. doi: 10.1105/tpc.114.133496

Charpentier, M., and Oldroyd, G. E. (2013). Nuclear calcium signaling in plants. Plant Physiol. 163, 496-503. doi: 10.1104/pp.113.220863

Chen, L., Song, Y., Li, S., Zhang, L., Zou, C., and Yu, D. (2012). The role of WRKY transcription factors in plant abiotic stresses. Biochim. Biophys. Acta 1819, 120-128. doi: 10.1016/j.bbagrm.2011.09.002

Choi, M. S., Kim, M. C., Yoo, J. H., Moon, B. C., Koo, S. C., Park, B. O., et al. (2005). Isolation of a calmodulin-binding transcription factor from rice (Oryza sativa L.). J. Biol. Chem. 280, 40820-40831. doi: 10.1074/jbc.M504616200

Colebatch, G., Desbrosses, G., Ott, T., Krusell, L., Montanari, O., Kloska, S., et al. (2004). Global changes in transcription orchestrate metabolic differentiation during symbiotic nitrogen fixation in Lotus japonicus. Plant J. 39, 487-512. doi: 10.1111/j.1365-313X.2004.02150.x

Cowie, A., Cheng, J., Sibley, C. D., Fong, Y., Zaheer, R., Patten, C. L., et al. (2006). An integrated approach to functional genomics: construction of a novel reporter gene fusion library for Sinorhizobium meliloti. Appl. Environ. Microbiol. 72, 7156-7167. doi: 10.1128/AEM.01397-06

Czaja, L. F., Hogekamp, C., Lamm, P., Maillet, F., Martinez, E. A., Samain, E.,et al. (2012). Transcriptional responses toward diffusible signals from symbiotic microbes reveal MtNFP- and MtDMI3-dependent reprogramming of host gene expression by arbuscular mycorrhizal fungal lipochitooligosaccharides. Plant Physiol. 159, 1671-1685. doi: 10.1104/pp.112.195990

DeFalco, T. A., Bender, K. W., and Snedden, W. A. (2010). Breaking the code: $\mathrm{Ca}^{2+}$ sensors in plant signalling. Biochem. J. 425, 27-40. doi: 10.1042/BJ20 091147

Denarie, J., Debelle, F., and Prome, J. C. (1996). Rhizobium lipochitooligosaccharide nodulation factors: signaling molecules mediating recognition and morphogenesis. Annu. Rev. Biochem. 65, 503-535. doi: 10.1146/annurev.bi.65.070196.002443

Doherty, C. J., Van Buskirk, H. A., Myers, S. J., and Thomashow, M. F. (2009). Roles for Arabidopsis CAMTA transcription factors in cold-regulated gene expression and freezing tolerance. Plant Cell 21, 972-984. doi: 10.1105/tpc.108. 063958

Du, L., Yang, T., Puthanveettil, S., and Poovaiah, B. W. (2011). "Decoding of calcium signal through calmodulin: calmodulin-binding proteins in plants," in Coding and Decoding of Calcium Signals in Plants, ed S. Luan (Berlin Heidelberg: Springer), 177-233. and LQ14C060001, and the National Natural Science Foundation of China (31401935). We are grateful to Professor Poovaiah from Washington State University and Professor Liqun Du from Hangzhou Normal University for their academic guidance and kind help.

\section{Supplementary Material}

The Supplementary Material for this article can be found online at: http://journal.frontiersin.org/article/10.3389/fpls.2015. 00459

Du, L. Q., Ali, G. S., Simons, K. A., Hou, J. G., Yang, T. B., Reddy, A. S. N., et al. (2009). $\mathrm{Ca}^{2+} /$ calmodulin regulates salicylic-acid-mediated plant immunity. Nature 457, 1154-1158. doi: 10.1038/nature07612

Engstrom, E. M., Ehrhardt, D. W., Mitra, R. M., and Long, S. R. (2002). Pharmacological analysis of nod factor-induced calcium spiking in Medicago truncatula. Evidence for the requirement of type IIA calcium pumps and phosphoinositide signaling. Plant Physiol. 128, 1390-1401. doi: 10.1104/pp.010691

Fedorova, M., van de Mortel, J., Matsumoto, P. A., Cho, J., Town, C. D., VandenBosch, K. A., et al. (2002). Genome-wide identification of nodulespecific transcripts in the model legume Medicago truncatula. Plant Physiol. 130, 519-537. doi: 10.1104/pp.006833

Finkler, A., Ashery-Padan, R., and Fromm, H. (2007). CAMTAs: calmodulinbinding transcription activators from plants to human. FEBS Lett. 581, 3893-3898. doi: 10.1016/j.febslet.2007.07.051

Galon, Y., Aloni, R., Nachmias, D., Snir, O., Feldmesser, E., Scrase-Field, S., et al. (2010b). Calmodulin-binding transcription activator 1 mediates auxin signaling and responds to stresses in Arabidopsis. Planta 232, 165-178. doi: 10.1007/s00425-010-1153-6

Galon, Y., Finkler, A., and Fromm, H. (2010a). Calcium-regulated transcription in plants. Mol. Plant 3, 653-669. doi: 10.1093/mp/ssq019

Galon, Y., Nave, R., Boyce, J. M., Nachmias, D., Knight, M. R., and Fromm, H. (2008). Calmodulin-binding transcription activator (CAMTA) 3 mediates biotic defense responses in Arabidopsis. FEBS Lett. 582, 943-948. doi: 10.1016/j.febslet.2008.02.037

Gimeno-Gilles, C., Lelièvre, E., Viau, L., Malik-Ghulam, M., Ricoult, C., Niebel, A., et al. (2009). ABA-mediated inhibition of germination is related to the inhibition of genes encoding cell-wall biosynthetic and architecture: modifying enzymes and structural proteins in Medicago truncatula embryo axis. Mol. Plant 2, 108-119. doi: 10.1093/mp/ssn092

Hirsch, A. M., and Fang, Y. (1994). Plant hormones and nodulation: what's the connection? Plant Mol. Biol. 26, 5-9. doi: 10.1007/BF00039514

Hu, B., Jin, J., Guo, A., Zhang, H., Luo, J., and Gao, G. (2014). GSDS 2.0: an upgraded gene feature visualization server. Bioinformatics 31, 1296-1297. doi: 10.1093/bioinformatics/btu817

Journet, E. P., El-Gachtouli, N., Vernoud, V., de Billy, F., Pichon, M., Dedieu, A., et al. (2001). Medicago truncatula ENOD11: a novel RPRP-encoding early nodulin gene expressed during mycorrhization in arbuscule-containing cells. Mol. Plant Microbe Interact. 14, 737-748. doi: 10.1094/MPMI.2001.14.6.737

Kaplan, B., Davydov, O., Knight, H., Galon, Y., Knight, M. R., Fluhr, R., et al. (2006). Rapid transcriptome changes induced by cytosolic $\mathrm{Ca}^{2+}$ transients reveal ABRE-related sequences as $\mathrm{Ca}^{2+}$-responsive cis elements in Arabidopsis. Plant Cell 18, 2733-2748. doi: 10.1105/tpc.106.042713

Kim, M. H., Kim, Y., Kim, J. W., Lee, H. S., Lee, W. S., Kim, S. K., et al. (2013a). Identification of Arabidopsis BAK1-associating receptor-like kinase 1 (BARK1) and characterization of its gene expression and brassinosteroid-regulated root phenotypes. Plant Cell Physiol. 54, 1620-1634. doi: 10.1093/pcp/pct106

Kim, Y., Park, S., Gilmour, S. J., and Thomashow, M. F. (2013b). Roles of CAMTA transcription factors and salicylic acid in configuring the low-temperature transcriptome and freezing tolerance of Arabidopsis. Plant J. 75, 364-376. doi: 10.1111/tpj.12205 
Koo, S. C., Choi, M. S., Chun, H. J., Shin, D. B., Park, B. S., Kim, Y. H., et al. (2009). The calmodulin-binding transcription factor OsCBT suppresses defense responses to pathogens in rice. Mol. Cells 27, 563-570. doi: 10.1007/s10059009-0081-4

Kudla, J., Batistic, O., and Hashimoto, K. (2010). Calcium signals: the lead currency of plant information processing. Plant Cell 22, 541-563. doi: 10.1105/tpc.109.072686

Laluk, K., Prasad, K. V. S. K., Savchenko, T., Celesnik, H., Dehesh, K., Levy, M., et al. (2012). The calmodulin-binding transcription factor SIGNAL RESPONSIVE1 is a novel regulator of glucosinolate metabolism and herbivory tolerance in Arabidopsis. Plant Cell Physiol. 53, 2008-2015. doi: $10.1093 / \mathrm{pcp} / \mathrm{pcs} 143$

Lévy, J., Bres, C., Geurts, R., Chalhoub, B., Kulikova, O., Duc, G., et al. (2004). A putative $\mathrm{Ca}^{2+}$ and calmodulin-dependent protein kinase required for bacterial and fungal symbioses. Science 303, 1361-1364. doi: 10.1126/science.1093038

Limpens, E., Moling, S., Hooiveld, G., Pereira, P. A., Bisseling, T., Becker, J. D., et al. (2013). cell- and tissue-specific transcriptome analyses of Medicago truncatula root nodules. PLOS ONE 8:e64377. doi: 10.1371/journal.pone. 0064377

Liu, J., Miller, S. S., Graham, M., Bucciarelli, B., Catalano, C. M., Sherrier, D. J., et al. (2006). Recruitment of novel calcium-binding proteins for root nodule symbiosis in Medicago truncatula. Plant Physiol. 141, 167-177. doi: 10.1104/pp.106.076711

Liu, J. H., Peng, T., and Dai, W. S. (2014). Critical cis-acting elements and interacting transcription factors: key players associated with abiotic stress responses in plants. Plant Mol. Biol. Rep. 32, 303-317. doi: 10.1007/s11105-0130667-z

Lohar, D. P., Sharopova, N., Endre, G., Penuela, S., Samac, D., Town, C., et al. (2006). Transcript analysis of early nodulation events in Medicago truncatula. Plant Physiol. 140, 221-234. doi: 10.1104/pp.105.070326

Maruyama-Nakashita, A., Nakamura, Y., Watanabe-Takahashi, A., Inoue, E., Yamaya, T., and Takahashi, H. (2005). Identification of a novel cis-acting element conferring sulfur deficiency response in Arabidopsis roots. Plant J. 42, 305-314. doi: 10.1111/j.1365-313X.2005.02363.x

Mathesius, U., Schlaman, H. R., Spaink, H. P., Of Sautter, C., Rolfe, B. G., and Djordjevic, M. A. (1998). Auxin transport inhibition precedes root nodule formation in white clover roots and is regulated by flavonoids and derivatives of chitin oligosaccharides. Plant J. 14, 23-34. doi: 10.1046/j.1365313X.1998.00090.x

Mitra, R. M., Gleason, C. A., Edwards, A., Hadfield, J., Downie, J. A., Oldroyd, G. E. D., et al. (2004). A Ca ${ }^{2+} /$ calmodulin-dependent protein kinase required for symbiotic nodule development: gene identification by transcript-based cloning. Proc. Natl. Acad. Sci. U.S.A. 101, 4701-4705. doi: 10.1073/pnas.0400595101

Molesini, B., Cecconi, D., Pii, Y., and Pandolfini, T. (2014). Local and systemic proteomic changes in Medicago truncatula at an early phase of Sinorhizobium meliloti infection. J. Proteome Res. 13, 408-421. doi: 10.1021/pr4009942

Moreau, S., Verdenaud, M., Ott, T., Letort, S., de Billy, F., Niebel, A., et al. (2011). Transcription reprogramming during root nodule development in Medicago truncatula. PLoS ONE 6:e16463. doi: 10.1371/journal.pone.0016463

Nakagawa, T., and Kawaguchi, M. (2006). Shoot-applied MeJA suppresses root nodulation in Lotus japonicus. Plant Cell Physiol. 47, 176-180. doi: $10.1093 / \mathrm{pcp} / \mathrm{pci} 222$

Nie, H. Z., Zhao, C. Z., Wu, G. H., Wu, Y. Y., Chen, Y. F., and Tang, D. Z. (2012). SR1, a Calmodulin-binding transcription factor, modulates plant defense and ethylene-induced senescence by directly regulating NDR1 and EIN3. Plant Physiol. 158, 1847-1859. doi: 10.1104/pp.111.192310

Oldroyd, G. E., and Downie, J. A. (2008). Coordinating nodule morphogenesis with rhizobial infection in legumes. Annu. Rev. Plant Biol. 59, 519-546. doi: 10.1146/annurev.arplant.59.032607.092839

Oldroyd, G. E. D., and Downie, J. A. (2006). Nuclear calcium changes at the core of symbiosis signalling. Curr. Opin. Plant Biol. 9, 351-357. doi: 10.1016/j.pbi.2006.05.003

Osakabe, Y., Yamaguchi-Shinozaki, K., Shinozaki, K., and Tran, L. S. P. (2014). ABA control of plant macroelement membrane transport systems in response to water deficit and high salinity. New Phytol. 202, 35-49. doi: 10.1111/nph.12613

Palma, F., Lopez-Gomez, M., Tejera, N. A., and Lluch, C. (2013). Salicylic acid improves the salinity tolerance of Medicago sativa in symbiosis with
Sinorhizobium meliloti by preventing nitrogen fixation inhibition. Plant Sci. 208, 75-82. doi: 10.1016/j.plantsci.2013.03.015

Pieterse, C. M., and Van Loon, L. C. (2004). NPR1: the spider in the web of induced resistance signaling pathways. Curr. Opin. Plant Biol. 7, 456-464. doi: 10.1016/j.pbi.2004.05.006

Poovaiah, B. W., Du, L. Q., Wang, H. Z., and Yang, T. B. (2013). Recent advances in calcium/calmodulin-mediated signaling with an emphasis on plant-microbe interactions. Plant Physiol. 163, 531-542. doi: 10.1104/pp.113.220780

Popescu, S. C., Popescu, G. V., Bachan, S., Zhang, Z. M., Seay, M., Gerstein, M., et al. (2007). Differential binding of calmodulin-related proteins to their targets revealed through high-density Arabidopsis protein microarrays. Proc. Natl. Acad. Sci. U.S.A. 104, 4730-4735. doi: 10.1073/pnas.0611615104

Punta, M., Coggill, P. C., Eberhardt, R. Y., Mistry, J., Tate, J., Boursnell, C., et al. (2012). The Pfam protein families database. Nucleic Acids Res. 40, D290-D301. doi: 10.1093/nar/gkr1065

Qiu, Y., Xi, J., Du, L., Suttle, J. C., and Poovaiah, B. W. (2012). Coupling calcium/calmodulin-mediated signaling and herbivore-induced plant response through calmodulin-binding transcription factor AtSR1/CAMTA3. Plant Mol. Biol. 79, 89-99. doi: 10.1007/s11103-012-9896-Z

Ranty, B., Aldon, D., and Galaud, J. P. (2006). Plant calmodulins and calmodulinrelated proteins: multifaceted relays to decode calcium signals. Plant Signal. Behav. 1, 96-104. doi: 10.4161/psb.1.3.2998

Reddy, A. S. N., Ali, G. S., Celesnik, H., and Day, I. S. (2011). Coping with stresses: roles of calcium- and calcium/calmodulin-regulated gene expression. Plant Cell 23, 2010-2032. doi: 10.1105/tpc.111.084988

Reddy, A. S. N., Reddy, V. S., and Golovkin, M. (2000). A calmodulin binding protein from Arabidopsis is induced by ethylene and contains a DNA-binding motif. Biochem. Biophys. Res. Commun. 279, 762-769. doi: $10.1006 /$ bbrc. 2000.4032

Reddy, V. S., Ali, G. S., and Reddy, A. S. N. (2002). Genes encoding calmodulinbinding proteins in the Arabidopsis genome. J. Biol. Chem. 277, 9840-9852. doi: 10.1074/jbc.M111626200

Ren, J., Wen, L., Gao, X., Jin, C., Xue, Y., and Yao, X. (2009). DOG 1.0: illustrator of protein domain structures. Cell Res. 19, 271-273. doi: 10.1038/cr.2009.6

Roux, B., Rodde, N., Jardinaud, M. F., Timmers, T., Sauviac, L., Cottret, L., et al. (2014). An integrated analysis of plant and bacterial gene expression in symbiotic root nodules using laser-capture microdissection coupled to RNA sequencing. Plant J. 77, 817-837. doi: 10.1111/tpj.12442

Rubio, V., Linhares, F., Solano, R., Martin, A. C., Iglesias, J., Leyva, A., et al. (2001). A conserved MYB transcription factor involved in phosphate starvation signaling both in vascular plants and in unicellular algae. Genes Dev. 15, 2122-2133. doi: 10.1101/gad.204401

Shaw, S. L., and Long, S. R. (2003). Nod factor elicits two separable calcium responses in Medicago truncatula root hair cells. Plant Physiol. 131, 976-984. doi: 10.1104/pp.005546

Singh, S., Katzer, K., Lambert, J., Cerri, M., and Parniske, M. (2014). CYCLOPS, a DNA-binding transcriptional activator, orchestrates symbiotic root nodule development. Cell Host Microbe 15, 139-152. doi: 10.1016/j.chom.2014.01.011

Singh, S., and Parniske, M. (2012). Activation of calcium- and calmodulindependent protein kinase (CCaMK), the central regulator of plant root endosymbiosis. Curr. Opin. Plant Biol. 15, 444-453. doi: 10.1016/j.pbi.2012.04.002

Soyano, T., and Hayashi, M. (2014). Transcriptional networks leading to symbiotic nodule organogenesis. Curr. Opin. Plant Biol. 20, 146-154. doi: 10.1016/j.pbi.2014.07.010

Spaink, H. P. (2000). Root nodulation and infection factors produced by rhizobial bacteria. Annu. Rev. Microbiol. 54, 257-288. doi: 10.1146/annurev.micro.54.1.257

Stacey, G., McAlvin, C. B., Kim, S. Y., Olivares, J., and Soto, M. J. (2006) Effects of endogenous salicylic acid on nodulation in the model legumes Lotus japonicus and Medicago truncatula. Plant Physiol. 141, 1473-1481. doi: 10.1104/pp.106.080986

Sun, J., Cardoza, V., Mitchell, D. M., Bright, L., Oldroyd, G., and Harris, J. M. (2006). Crosstalk between jasmonic acid, ethylene and Nod factor signaling allows integration of diverse inputs for regulation of nodulation. Plant J. 46, 961-970. doi: 10.1111/j.1365-313X.2006.02751.x

Suzuki, A., Akune, M., Kogiso, M., Imagama, Y., Osuki, K., Uchiumi, T., et al. (2004). Control of nodule number by the phytohormone abscisic Acid in 
the roots of two leguminous species. Plant Cell Physiol. 45, 914-922. doi: $10.1093 / \mathrm{pcp} / \mathrm{pch} 107$

Swainsbury, D. J. K., Zhou, L., Oldroyd, G. E. D., and Bornemann, S. (2012). Calcium ion binding properties of Medicago truncatula calcium/calmodulin-dependent protein kinase. Biochemistry 51, 6895-6907. doi: 10.1021/bi300826m

van Noorden, G. E., Ross, J. J., Reid, J. B., Rolfe, B. G., and Mathesius, U. (2006). Defective long-distance auxin transport regulation in the Medicago truncatula super numeric nodules mutant. Plant Physiol. 140, 1494-1506. doi: 10.1104/pp.105.075879

Wang, G., Zeng, H., Hu, X., Zhu, Y., Chen, Y., Shen, C., et al. (2014). Identification and expression analyses of calmodulin-binding transcription activator genes in soybean. Plant Soil 386, 205-221. doi: 10.1007/s11104-014-2267-6

Williams, M. E., Foster, R., and Chua, N. H. (1992). Sequences flanking the hexameric G-box core CACGTG affect the specificity of protein binding. Plant Cell 4, 485-496. doi: 10.1105/tpc.4.4.485

Yang, T., and Poovaiah, B. W. (2000). An early ethylene up-regulated gene encoding a calmodulin-binding protein involved in plant senescence and death. J. Biol. Chem. 275, 38467-38473. doi: 10.1074/jbc.M003566200

Yang, T. B., Peng, H., Whitaker, B. D., and Conway, W. S. (2012). Characterization of a calcium/calmodulin-regulated SR/CAMTA gene family during tomato fruit development and ripening. BMC Plant Biol. 12:19. doi: 10.1186/1471-222 9-12-19

Yang, T. B., and Poovaiah, B. W. (2002). A calmodulin-binding/CGCG box DNAbinding protein family involved in multiple signaling pathways in plants. J. Biol. Chem. 277, 45049-45058. doi: 10.1074/jbc.M207941200
Yang, T. B., and Poovaiah, B. W. (2003). Calcium/calmodulinmediated signal network in plants. Trends Plant Sci. 8, 505-512. doi: 10.1016/j.tplants.2003.09.004

Yano, K., Yoshida, S., Muller, J., Singh, S., Banba, M., Vickers, K., et al. (2008). CYCLOPS, a mediator of symbiotic intracellular accommodation. Proc. Natl. Acad. Sci. U.S.A. 105, 20540-20545. doi: 10.1073/pnas.0806 858105

Young, N. D., Debelle, F., Oldroyd, G. E. D., Geurts, R., Cannon, S. B., Udvardi, M. K., et al. (2011). The Medicago genome provides insight into the evolution of rhizobial symbioses. Nature 480, 520-524. doi: 10.1038/nature 10625

Zhang, N., Venkateshwaran, M., Boersma, M., Harms, A., Howes-Podoll, M., den Os, D., et al. (2012). Metabolomic profiling reveals suppression of oxylipin biosynthesis during the early stages of legume-rhizobia symbiosis. FEBS Lett. 586, 3150-3158. doi: 10.1016/j.febslet.2012.06.046

Conflict of Interest Statement: The authors declare that the research was conducted in the absence of any commercial or financial relationships that could be construed as a potential conflict of interest.

Copyright (C) 2015 Yang, Sun, Xu, Pi, Wang, Wang and Shen. This is an open-access article distributed under the terms of the Creative Commons Attribution License (CC $B Y)$. The use, distribution or reproduction in other forums is permitted, provided the original author(s) or licensor are credited and that the original publication in this journal is cited, in accordance with accepted academic practice. No use, distribution or reproduction is permitted which does not comply with these terms. 